\title{
PEMODELAN DAN SIMULASI REVERSE FLOW REACTOR UNTUK OKSIDASI KATALITIK METANA: PENGEMBANGAN PROSEDUR OPERASI START-UP
}

\author{
Yogi Wibisono Budhi*, Teguh Kurniawan, Yazid Bindar \\ Program Studi Teknik Kimia, Fakultas Teknologi Industri, \\ Institut Teknologi Bandung \\ Jalan Ganesha 10,Bandung 40132 \\ Email:Y.Wibisono@che.itb.ac.id
}

\begin{abstract}
Abstrak
Di dalam studi pemodelan dan simulasi ini, berbagai prosedur operasi reverse flow reactor (RFR) selama start-up untuk oksidasi katalitik metana encer (1\%-v) dikaji dengan target sistem beroperasi secara ototermal, konversi metana tinggi, waktu pencapaian kondisi tunak semu (pseudosteady state) cepat, dan beban panas rendah. Pemodelan reaktor didasarkan pada model satu dimensi dan pseudohomogeneous untuk neraca massa, serta heterogen untuk neraca energi. Pemanasan katalis saja pada awal reaksi (Prosedur 1) tidak dapat mencapai kondisi reaktor yang ototermal. Pemanasan katalis dan inert bagian kiri (Prosedur 2) mampu mencapai kondisi reaktor yang ototermal hingga switching time (ST) 230 detik. Pemanasan seluruh bagian reaktor pada awal reaksi (Prosedur 3) mampu mencapai kondisi reaktor yang ototermal pada ST paling lama 300 detik. Prosedur start-up 2 dan 3 untuk ST 200 detik sama-sama mencapai waktu pseudosteady state pada 1000 detik dengan konversi total selama start-up masing-masing 95\% dan 99\%. Meskipun Prosedur 3 memberikan konversi sedikit lebih tinggi daripada Prosedur 2, namun beban panas Prosedur 3 mencapai dua kali lebih besar daripada Prosedur 2.
\end{abstract}

Kata kunci: emisi metana, pemodelan dan simulasi, prosedur start-up, reverse flow reactor, switching time.

\begin{abstract}
.
In this modelling and simulation study, three operating procedures during start-up of lean methane $(1 \%-v)$ oxidation in reverse flow reactor (RFR) have been investigated to get autothermal condition, high methane conversion, faster pseudo steady state, and low preheating energy requirement. The RFR model developed based on one-dimension pseudohomogeneous model for mass balance and heterogeneous model for energy balance. Procedure 1 , the preheating was employed only on the catalyst zone, fails to conduct the autothermal reaction and to achieve high conversion.. Procedure 2, the preheating was employed for inert and catalyst of left side only, able to achieve the autothermal up to switching time (ST) $230 \mathrm{~s}$. Procedure 3, the preheating was employed along the reactor bed, achieve the autothermal condition up to ST $300 \mathrm{~s}$. Procedure 2 and 3 achieved the pseudosteadystate at $1000 \mathrm{~s}$ for ST $200 \mathrm{~s}$ with total conversion during start-up are $95 \%$ and $99 \%$. The conversion of Procedure 3 higher than Procedure 2, unfortunately the heat load of Procedure 3 two times higher than Procedure 2.
\end{abstract}

Keywords: modelling and simulation, catalytic methane oxidation, start-up procedure, reverse flow reactor, switching time.

${ }^{*}$ korespondensi 


\section{Pendahuluan}

Metana merupakan salah gas rumah kaca yang memberikan efek pemanasan global 21 kali lebih besar daripada karbondioksida. Sumber emisi metana utamanya berasal dari pertambangan batubara, pengeboran minyak, gas alam, dan fermentasi anaerob bahan-bahan organik. Emisi metana dari pengeboran minyak dan gas alam serta pada waktu pendistribusiannya mencapai angka 15\% dari total sumber emisi metana. Emisi metana pada stasiun kompresor perpipaan gas alam menyumbangkan angka tertinggi sebesar $27 \%$ dari emisi metana pada pengeboran minyak, gas alam, dan pendistribusiannya (Moore dkk., 1998) dengan konsentrasi emisi metana sebesar 0,1-1 \%-v (Litto dkk., 2007). Salah satu cara untuk mengurangi emisi metana dapat dilakukan dengan mengoksidasi metana menjadi karbondioksida. Oksidasi metana dapat menurunkan potensi metana terhadap pemanasan global hingga 87\% (Hayes, 2004).

Metana merupakan senyawa yang mudah terbakar. Rentang persen volume daerah keterbakaran adalah 5-16\% metana dalam udara (Hayes dan Kolaczkowski, 1997). Emisi metana berkonsentrasi tinggi dapat mudah terbakar dengan menggunakan teknologi konvensional. Pada konsentrasi kurang dari 5 \%-v metana, reaksi pembakaran tidak dapat berlangsung dengan teknologi pembakaran konvensional.

Teknologi yang dikembangkan untuk membakar metana pada konsentrasi rendah adalah dengan menggunakan reaktor katalitik unggun tetap. Oksidasi katalitik dengan menggunakan katalis yang tepat memungkinkan reaksi berlangsung pada rentang konsentrasi umpan metana yang lebih lebar (Lee dan Trimm, 1995). Berbagai katalis yang diteliti untuk keperluan oksidasi

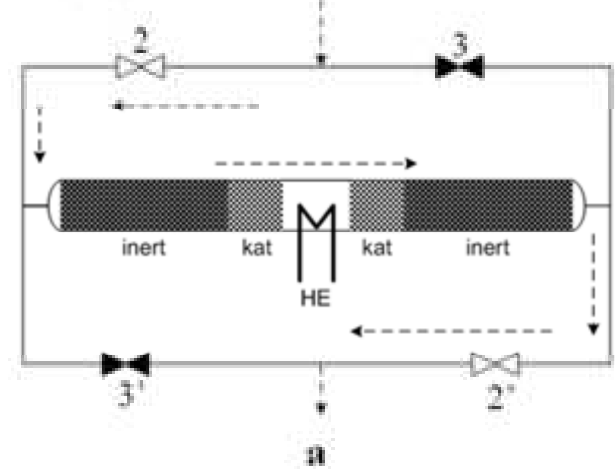

metana umumnya berasal dari golongan logam mulia (Pd, Rh, dan $\mathrm{Pt}$ ) dengan penyangga alumina $\left(\mathrm{Al}_{2} \mathrm{O}_{3}\right)$ (Otto, 1989; Lee dan Trimm., 1995; Hayes dkk., 2001).

Metana berkonsentrasi rendah yang dioksidasi dengan desain reaktor katalitik yang tepat tidak hanya berpotensi mengurangi emisi metana, namun juga berpotensi untuk pemanfaatan panas yang dihasilkan dari reaksi pembakarannya. Teknologi oksidasi katalitik metana dapat dimanfaatkan di sumber-sumber emisi metana berkonsentrasi rendah seperti tambang batubara, stasiun kompresor, sumur-sumur gas berkonsentrasi rendah untuk menghasilkan listrik bagi keperluan lingkungan sekitarnya.

Reaktor unggun tetap untuk keperluan reaksi oksidasi metana berkonsentrasi rendah perlu dirancang khusus agar panas yang diperlukan selama reaksi mampu dipenuhi dari panas hasil reaksi sendiri atau dengan kata lain reaktor bersifat ototermal. Kondisi ototermal pada reaktor unggun tetap dapat dicapai dengan merancang reaktor unggun tetap dengan pertukaran panas tipe rekuperatif atau tipe regeneratif (Kolios dkk., 2000). Efisiensi panas untuk tipe regeneratif dapat mencapai 95\%. Harga efisiensi tipe regeneratif itu lebih besar daripada tipe rekuperatif yang hanya mencapai $75 \%$ (Baressi dkk., 2007).

Salah satu contoh pertukaran panas tipe regeneratif adalah Reverse Flow Reactor (RFR) (Gambar 1). Reaksi dalam RFR dapat berlangsung secara ototermal meskipun temperatur reaksi sangat tinggi dan kenaikan temperatur adiabatis relatif kecil. Fenomena ini dapat terjadi karena unggun katalis khususnya posisi di ujung-ujung reaktor bertindak sebagai penukar panas tipe regeneratif (Eigenberger dan Nieken, 1989).

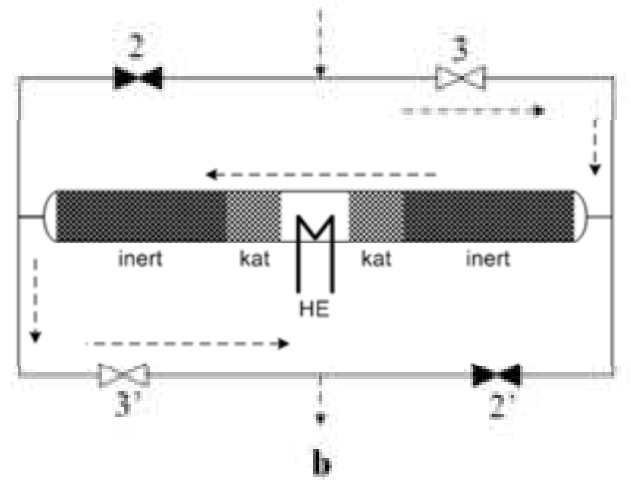

Gambar 1. Ilustrasi reverse flow reactor 
Operasi RFR katalitik menawarkan berbagai keunggulan berkaitan dengan kondisi dinamik yang terjadi selama reaksi berlangsung. Kondisi dinamik untuk konsentrasi dan temperatur pada RFR tercipta dengan cara membolak-balik arah aliran masuk umpan. Aliran umpan yang asalnya dari kiri ke kanan diubah secara periodik menjadi dari kanan ke kiri dalam siklus waktu tertentu. Matros dan Bunimovich (1996) menjelaskan bahwa kondisi dinamik akan meningkatkan konversi, selektivitas dan atau temperatur dalam reaktor.

Riset eksperimental RFR katalitik telah berhasil dilakukan oleh para peneliti untuk mengoksidasi metana berkonsentrasi rendah dengan gas umpan bertemperatur lingkungan (Sapoundjiev dan Aube, 1999; Salomons dkk., 2003; Kushwaha dkk., 2004; Hayes, 2004). Hasil penelitian menunjukkan bahwa selain dapat mengurangi efek gas rumah kaca, oksidasi katalitik metana berkonsentrasi rendah pada RFR berpotensi menghasilkan ekstrak panas (Sapoundjiev dan Aube, 1999; Kushwaha dkk., 2005). Energi ekstrak panas dapat dikonversikan menjadi energi listrik untuk keperluan lingkungan sekitar sumber metana berkonsentrasi rendah.

Unjuk kerja RFR yang ditinjau dari sifat ototermal oksidasi katalitik metana berkonsentrasi rendah dipengaruhi oleh konsentrasi umpan, switching time (ST), dan kecepatan linier umpan (Salomon dkk., 2003). Penelitian lebih jauh mengenai pengaruh parameter desain khususnya tipe inert berupa monolit dan unggun terhadap unjuk kerja RFR dilakukan oleh Kushwaha dkk. (2004). Pemakaian tipe inert monolit akan mengurangi hilang tekan sepanjang reaktor daripada tipe inert unggun.

Ada dua kriteria yang harus dipenuhi selama operasi RFR berlangsung khususnya untuk reaksi eksotermik, yaitu reaktor tidak padam karena kekurangan panas dan tidak meleleh oleh kelebihan panas. Simulasi simple logic-based control untuk memenuhi kedua kritera tersebut dikaji dengan penetapan variabel kontrol berupa temperatur reaktor pada laju alir umpan tertentu dengan variabel yang menjadi respon adalah switching time (Balaji dan Lakshminarayanan, 2005). Prosedur operasi RFR untuk oksidasi metana dengan konsentrasi berfluktuatif telah berhasil dikembangkan melalui penentuan ST yang tepat dengan memperhatikan kedua kriteria tersebut (Effendy dkk., 2009).

Pemodelan metematik dilakukan untuk memahami karakteristik serta untuk keperluan perancangan RFR. Pemodelan satu dimensi (1D) homogen semu untuk oksidasi katalitik metana dengan memasukkan suku dispersi aksial serta menghilangkan suku dinamik neraca massa menghasilkan profil yang cukup berkesesuaian dengan data-data eksperimental (Eigenberger dan Nieken, 1988). Model heterogen untuk neraca energi dikembangkan oleh Gawdzik dan Rakowski (1989) tanpa melibatkan suku-suku dispersi. Model heterogen dengan memasukkan sukusuku dispersi dijelaskan oleh Matros dan Bunimovich (1996). Penyederhanaan model heterogen dapat dilakukan dengan mengabaikan suku-suku dinamik pada neraca gasnya (Gawdzik dan Rakowski, 1989; Matros dan Bunimovich, 1996).

\section{Metodologi}

Metode start-up sangat menentukan keberlangsungan reaksi oksidasi katalitik di dalam RFR secara ototermal. RFR dapat beroperasi secara ototermal jika reaksi oksidasi katalitik menghasilkan panas dengan jumlah yang cukup untuk memanaskan umpan. Dengan demikian, salah satu masalah yang dikaji dalam studi ini adalah penentuan metode start-up yang dapat menjaga keberlangsungan reaksi oksidasi katalitik metana secara ototermal dengan beban panas start-up yang kecil dalam waktu pencapaian kondisi tunak semu (pseudosteady state) yang singkat dan konversi tinggi.

Simulasi diawali dengan operasi reaktor unggun tetap - satu arah. Simulasi dilakukan untuk mengetahui pengaruh suhu reaksi terhadap kelakuan reaksi oksidasi metana. Hasil simulasi reaksi oksidasi di reaktor unggun tetap - satu arah digunakan sebagai dasar penentuan kondisi operasi RFR. Setelah kondisi operasi terbaik diperoleh, simulasi RFR diawali dengan variabel metode start-up. Pemilihan metode start-up RFR merupakan bagian yang penting dalam pengoperasian reaksi oksidasi metana dalam RFR. Metoda start-up yang akan diuji coba dalam kajian ini adalah (Prosedur startup 1) pemanasan hanya dilakukan di zona katalis, zona inert berada dalam kondisi dingin (temperatur zona inert sama dengan temperatur lingkungan; (Prosedur start-up 
2) pemanasan dilakukan pada zona inert dan katalis bagian kiri; (Prosedur start-up 3) pemanasan dilakukan pada seluruh unggun reaktor (inert dan katalis bagian kiri maupun kanan). Pada bagian ini, simulasi dilakukan pada konsentrasi umpan tetap, yaitu $1 \%-\mathrm{v}$ metana.

Model matematik yang dikembangkan adalah model homogen semu (pseudohomogeneous) untuk neraca massa dan heterogen untuk neraca energi. Model tersebut telah digunakan oleh Matros dkk. (1996). Pemodelan homogen semu untuk neraca massa dilakukan dengan pertimbangan hambatan perpindahan massa sangat kecil pada reaksi oksidasi katalitik metana. Sementara itu, pemodelan heterogen untuk neraca energi dilakukan dengan pertimbangan pada temperatur tinggi hambatan perpindahan panas akan sangat berarti. Adapun pemodelan dilakukan dalam 5 zona, yaitu zona 1 (inert), zona 2 (katalis), zona 3 (ekstraksi panas), zona 4 (katalis), dan zona 5 (inert) (Gambar 2).

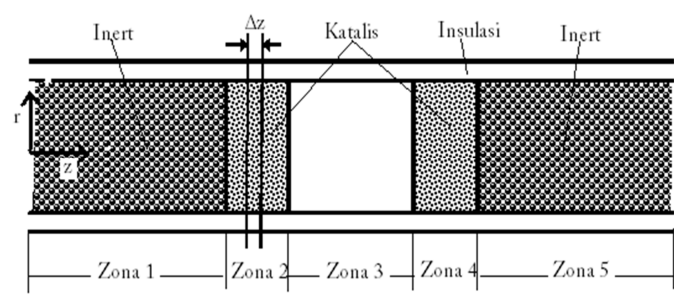

Gambar 2. Elemen volume dan pembagian zona

Pemodelan matematik dilakukan dengan asumsi-asumsi sebagai berikut.

a. Panas reaksi hanya diserap oleh inert dan katalis.

b. Data kinetika reaksi diambil dari literature.

c. Parameter-parameter model dihitung berdasarkan persamaan empirik.

d. Hilang tekan sepanjang reaktor sangat kecil.

e. Perpindahan panas dan massa ke arah radial diabaikan.

Akhirnya, persamaan model matematik beserta kondisi batas-batasnya untuk RFR disajikan dalam persamaan 1-13.

$$
\begin{aligned}
& \frac{\partial C}{\partial t}=D_{\text {eff }} \frac{\partial^{2} C}{\partial z^{2}}-u \frac{\partial C}{\partial z}+\left(-r_{M}\right) \\
& \epsilon \rho_{g} c_{g} \frac{\partial T_{g}}{\partial t}=-u \rho c_{g} \frac{\partial T_{g}}{\partial z}-\alpha_{0} a_{v}\left(T_{g}-T_{s}\right)- \\
& \frac{4 U_{\text {overall }}}{d}\left(T_{g}-T_{\text {ruang }}\right)-Q_{\text {ekstrak }}
\end{aligned}
$$

$$
\begin{aligned}
& {\left[(1-\epsilon) \epsilon_{p} \rho_{s} c_{s}+\epsilon_{g} \rho_{g} c_{g}\right] \frac{\partial T_{s}}{\partial t}=k_{e f f} \frac{\partial^{2} T_{s}}{\partial x^{2}}+} \\
& \alpha_{0} a_{v}\left(T_{g}-T_{s}\right)+(-\Delta H) r_{M}
\end{aligned}
$$

Persamaan kinetika reaksi oksidasi untuk katalis $0,5 \%$-Pt $/ \mathrm{Al}_{2} \mathrm{O}_{3}$ adalah sebagai berikut (Bosomoiu dkk., 2008).

$r_{M}=2,24 \times 10^{7} \exp \left(-98324 /_{R T}\right) C$

Kondisi awal

$C=C_{\text {input }}, \quad T_{g}=T_{\text {g,input }}$,

Bagian kiri reaktor

$T_{s, \text { inert }}=T_{s, \text { inert } 0}, \quad T_{s, \text { katalis }}=T_{s, \text { katalis } 0}(6)$

Bagian kanan reaktor

$T_{s, \text { inert }}=T_{s, \text { inert } 0}, \quad T_{s, \text { katalis }}=T_{s, \text { katalis } 0}(7)$

Kondisi batas:

Pada $\mathrm{z}=0$

$D_{\text {eff }} \frac{\partial C}{\partial z}=\frac{\left(1+\mathrm{K}_{(t)}\right)}{2} u L\left(C-C_{\text {inp }}\right)$

$k_{\text {eff }} \frac{\partial T_{g}}{\partial z}=\frac{\left(1+\mathrm{K}_{(t)}\right)}{2} u c_{g} \rho_{g}\left(T_{g}-T_{g, \text { inp }}\right)$

$\frac{\partial T_{s}}{\partial z}=0$

Pada $\mathrm{z}=\mathrm{L}$

$D_{\text {eff }} \frac{\partial C}{\partial z}=\frac{\left(1-\mathrm{K}_{(t)}\right)}{2} u L\left(C-C_{\text {inp }}\right)$

$k_{\text {eff }} \frac{\partial T_{g}}{\partial z}=\frac{\left(1-\mathrm{K}_{(t)}\right)}{2} u c_{g} \rho_{g}\left(T_{g}-T_{g, \text { inp }}\right)$

$\frac{\partial T_{s}}{\partial z}=0$

$\mathrm{K}_{(t)}$ bernilai +1 untuk arah aliran ke kanan dan -1 untuk aliran ke kiri.

Parameter operasi RFR dan kondisi umpan disajikan pada Tabel 1. Sedangkan pertelaan detail rancangan RFR yang digunakan dalam simulasi disajikan pada Tabel 2.

Tabel 1. Kondisi umpan dan operasi

\begin{tabular}{ll}
\hline Parameter operasi & Harga \\
\hline Temperatur gas umpan, $\mathrm{T}_{\mathrm{g}, \mathrm{inp}}$ & $30{ }^{\circ} \mathrm{C}$ \\
Laju alir linier gas umpan, $u$ & $0,7 \mathrm{~m} / \mathrm{s}$ \\
Tekanan, $\mathrm{P}$ & $1,5 \mathrm{~atm}$ \\
\hline
\end{tabular}

Salah satu metode numerik untuk menyelesaikan persamaan differensial parsial adalah Finite Element Method (FEM). FEM dikembangkan pertama kali pada tahun 1940 dalam bidang mekanika struktural, sedangkan istilah finite element sendiri baru diperkenalkan oleh Clough pada tahun 1960. Metode Galerkin menjadi kerangka 
Pemodelan dan Simulasi Reverse Flow Reactor (Y. W. Budhi, T. Kurniawan, Y. Bindar)

Tabel 2. Rancangan RFR untuk oksidasi katalitik metana

\begin{tabular}{ll}
\hline \multicolumn{1}{c}{ Spesifikasi rancangan } & \multicolumn{1}{c}{ Kuantitas } \\
\hline Diameter reaktor & $0,0147 \mathrm{~m}$ \\
Panjang total reaktor & $0,26 \mathrm{~m}$ \\
Koefisien perpindahan panas reaktor & $131 \mathrm{~W} / \mathrm{m}^{2} . \mathrm{K}$ \\
Zona inert & \\
$\quad$ Panjang per segmen inert & $0,1 \mathrm{~m}$ \\
$\quad$ Material unggun inert & Alumina \\
$\quad$ Diameter rata-rata partikel inert & 0,003 \\
$\quad$ Luas permukaan spesifik inert & $2000 \mathrm{~m}^{2} / \mathrm{m}^{3}$ \\
Zona katalis & \\
$\quad$ Panjang zona katalis & $0,01 \mathrm{~m}$ \\
$\quad$ Material unggun katalis & $\mathrm{Pt} / \gamma-\mathrm{Al}_{2} \mathrm{O}_{3}$ \\
$\quad$ Diameter rata-rata partikel katalis & $1 \times 10^{-5} \mathrm{~m}$ \\
$\quad$ Luas permukaan spesifik katalis & $2000 \mathrm{~m}^{2} / \mathrm{m}^{3}$ \\
Zona pengambilan panas & $0,04 \mathrm{~m}$ \\
Fraksi kosong dalam unggun katalis, $\varepsilon$ & 0,36 \\
Fraksi kosong katalis, $\varepsilon_{\mathrm{p}}$ & 0,451 \\
Fraksi gas dalam unggun katalis, $\varepsilon_{\mathrm{g}}$ & 0,65 \\
Fraksi solid dalam unggun katalis, $\varepsilon_{\mathrm{sk}}$ & 0,35 \\
Fraksi gas dalam unggun inert, $\varepsilon_{\mathrm{i}}$ & 0,36 \\
Fraksi solid dalam unggun inert, $\varepsilon_{\mathrm{si}}$ & 0,64 \\
\hline
\end{tabular}

Prosedur simulasi pada penelitian ini disajikan pada Gambar 3.

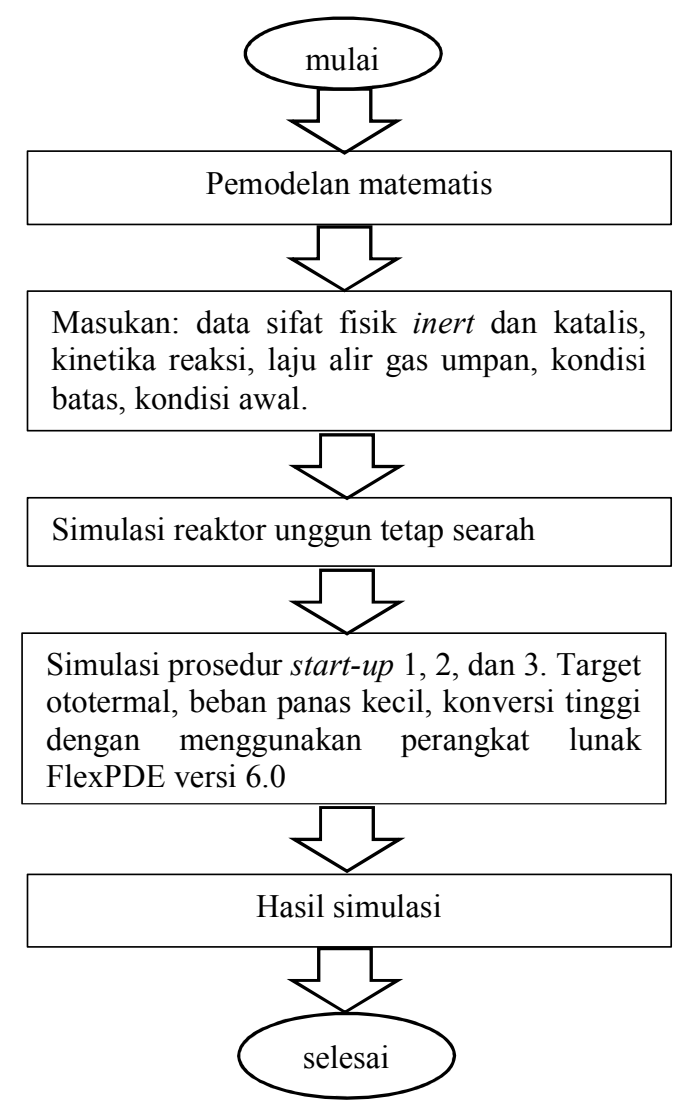

Gambar 3 Diagram alir prosedur simulasi reaksi oksidasi dalam RFR 
penyelesaian numerik dengan menggunanan FEM (Schäfer, 2006). Pada prinsipnya metode Galerkin merupakan metode numerik untuk mengkonversi operator matematika kontinyu dalam hal ini persamaan diferensial parsial menjadi persoalan diskrit.

Perangkat lunak berbasis FEM yang digunakan pada penelitian ini adalah FlexPDE versi 6.0. Prosedur operasi yang dilakukan oleh FlexPDE untuk menyelesaikan PDP adalah membangun model elemen, menyelesaikannya secara numerik, dan menampilkan hasil dalam format grafik dan tabulasi (PDE Solutions, 2010).

\section{Hasil dan Pembahasan 3.1 Operasi satu arah}

Reaksi oksidasi metana untuk umpan campuran metana-udara dengan konsentrasi $1 \%$-v metana pada temperatur lingkungan tidak dapat bereaksi dengan operasi searah menggunakan reaktor unggun tetap meskipun katalis telah dipanaskan terlebih dahulu hingga temperatur $550{ }^{\circ} \mathrm{C}$. Berdasarkan simulasi, reaksi oksidasi metana hanya dapat berlangsung dengan operasi searah dan mencapai konversi $100 \%$ pada temperatur umpan di atas $375{ }^{\circ} \mathrm{C}$ dengan temperatur awal reaktor $550{ }^{\circ} \mathrm{C}$ (Gambar 4). Hal ini berarti, umpan harus terus-menerus dipanaskan minimal hingga temperatur 375 ${ }^{\circ} \mathrm{C}$, agar reaksi tidak padam. Pada kondisi tunak, temperatur aliran keluar reaktor mencapai harga $1000^{\circ} \mathrm{C}$ dan $1200^{\circ} \mathrm{C}$ masingmasing untuk temperatur umpan $375^{\circ} \mathrm{C}$ dan $550{ }^{\circ} \mathrm{C}$. Aliran gas keluar reaktor ini membawa panas yang akan terbuang percuma jika tidak dimanfaatkan.

Waktu pencapaian kondisi tunak dan konversi $100 \%$ pada operasi searah juga dipengaruhi oleh temperatur umpan. Pada

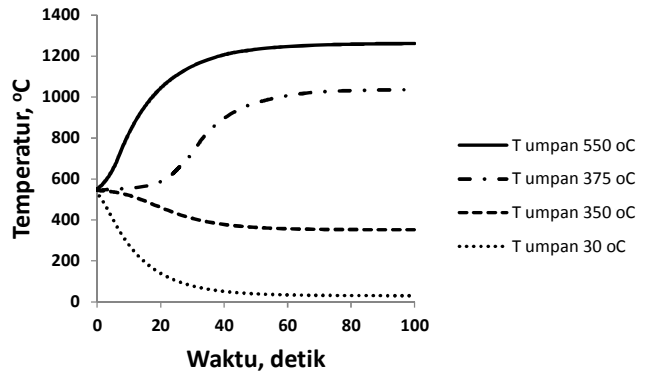

(a) temperatur umpan yang lebih tinggi waktu untuk mencapai kondisi tunak dan konversi $100 \%$ lebih cepat. Untuk umpan dengan temperatur $375{ }^{\circ} \mathrm{C}$, waktu mencapai temperatur tunak dan konversi $100 \%$ adalah 70 dan 30 detik. Sedangkan, umpan dengan temperatur $550{ }^{\circ} \mathrm{C}$ mencapai temperatur tunak dan konversi $100 \%$ pada 50 dan 8 detik.Temperatur reaksi pada saat konversi $100 \%$ tercapai adalah $745{ }^{\circ} \mathrm{C}$ baik untuk umpan bertemperatur $375^{\circ} \mathrm{C}$ maupun $550^{\circ} \mathrm{C}$.

Untuk mengetahui temperatur reaksi terbaik dalam melangsungkan reaksi oksidasi metana pada operasi searah khususnya selama periode dinamik dialurkan grafik yang menggambarkan hubungan antara temperatur reaksi dengan waktu reaksi pada saat konversi $100 \%$ tercapai (Gambar 5a). Kurva terlihat landai kira-kira pada temperatur reaktor $500{ }^{\circ} \mathrm{C}$ (temperatur umpan dan awal katalis $500{ }^{\circ} \mathrm{C}$ ). Selanjutnya, temperatur awal $500{ }^{\circ} \mathrm{C}$ akan digunakan dalam simulasi prosedur start-up.

Konversi total selama 100 detik untuk temperatur umpan $500{ }^{\circ} \mathrm{C}$ dengan pemanasan awal katalis hingga $500{ }^{\circ} \mathrm{C}$ adalah 90\% (Gambar 5b). Konversi total praktis 100\% selama reaktor dioperasikan 100 detik diperoleh pada temperatur reaktor diatas $600{ }^{\circ} \mathrm{C}$. Namun demikian, beban panas yang harus dipasok ke dalam sistem reaktor unggun searah akan sangat besar. Untuk mengurangi beban panas tersebut, maka dilakukan operasi bolak-balik pada reaktor unggun dengan penambahan inert pada ujung-ujung reaktor.

Simulasi operasi bolak-balik di dalam reverse flow reactor (RFR) dilakukan untuk metana-udara berkonsentrasi $1 \%-\mathrm{v}$ metana pada temperatur $30{ }^{\circ} \mathrm{C}$ dengan pemanasan awal inert dan katalis hingga temperatur 500 ${ }^{\circ} \mathrm{C}$. Hasil simulasi disajikan bersama-sama dengan operasi searah pada kondisi yang

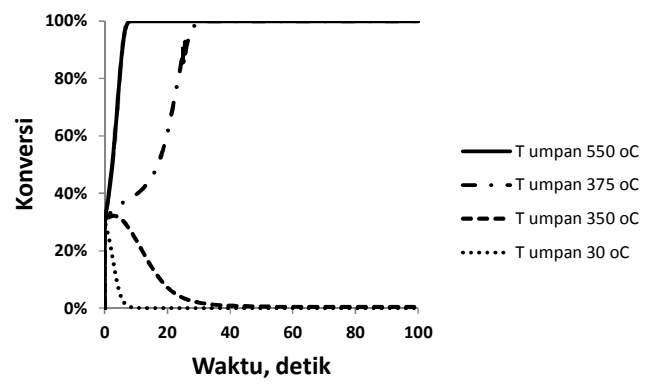

(b)

Gambar 4. Profil dinamik T (a) dan X (b) pada berbagai T umpan dalam operasi satu arah 


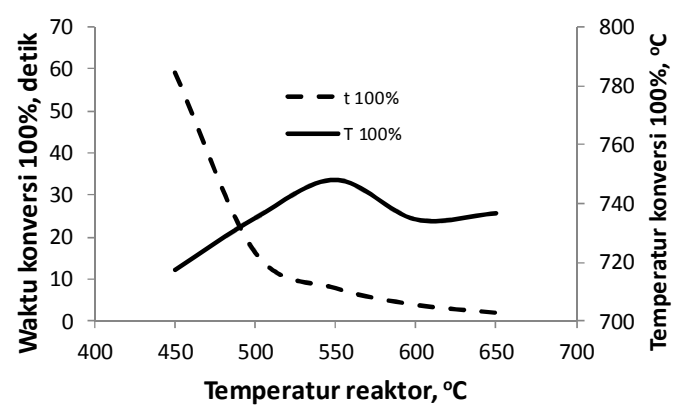

(a)

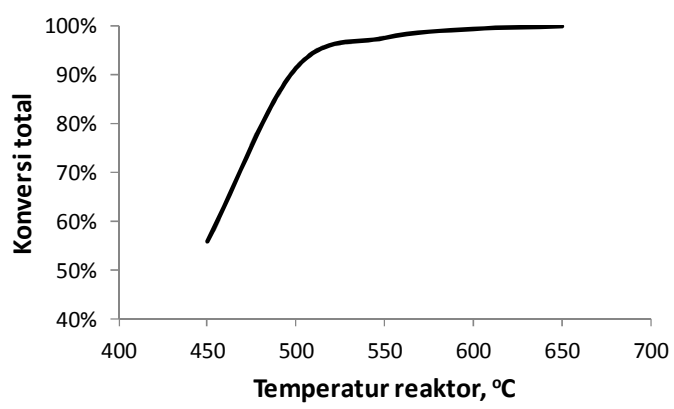

(b)

Gambar 5. (a) Waktu (t 100\%) dan temperatur (T 100\%) mencapai konversi $100 \%$ sesaat pada berbagai temperatur reaktor dan umpan yang sama.(b) Konversi total pada berbagai temperatur reaktor dari $\mathrm{t}=\mathbf{0}$ detik s.d. $\mathrm{t}=\mathbf{1 0 0}$ detik

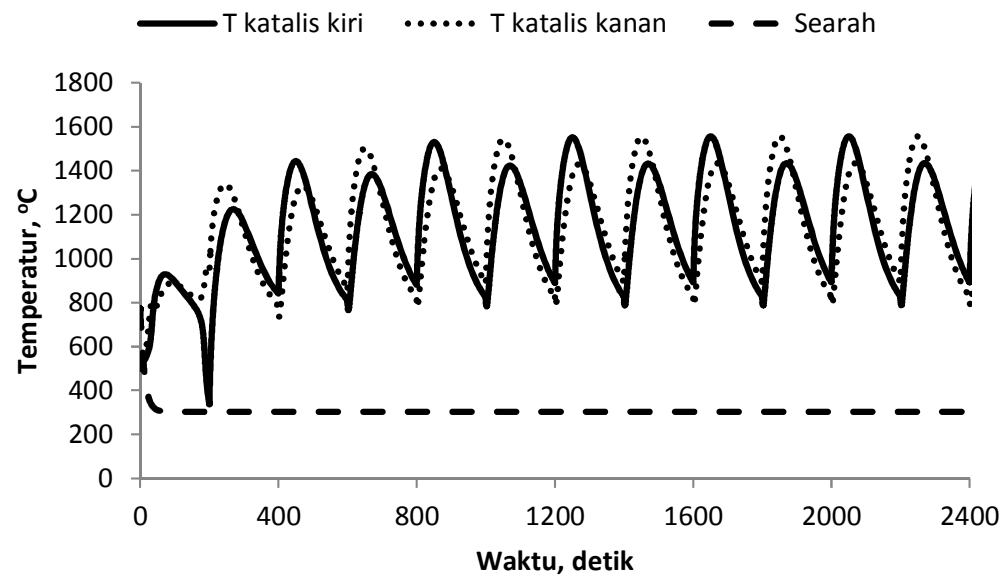

Gambar 6. Perbandingan profil dinamik temperatur operasi satu arah dan bolak-balik pada temperatur umpan $30^{\circ} \mathrm{C}$, temperatur mula-mula inert dan katalis $500{ }^{\circ} \mathrm{C}$ dan ST 200 detik untuk operasi bolak-balik

sama (Gambar 6). Operasi searah tidak mampu melangsungkan reaksi, sedangkanoperasi bolak-balik mampu mencapai kondisi ototermal dan tunak semu. Konversi total operasi searah hanya $0,01 \%$ jauh lebih kecil daripada operasi bolak-balik yang mencapai 99,6\% pada kondisi yang sama.

Profil dinamik temperatur katalis bagian kiri pada RFR setelah kondisi tunak semu tercapai menunjukkan pola bukit tinggi-bukit rendah. Bukit tinggi berarti panas berasal dari katalis sebelah kiri kemudian terbawa aliran sehingga mampu memanaskan katalis sebelah kanan. Dengan kalimat lain, bukit tinggi berarti tempat terjadinya reaksi. Ketika aliran umpan dibalik menjadi dari arah kanan, pada bagian katalis kiri RFR tercipta bukit kecil yang menunjukkan bahwa panas yang dihasilkan dari reaksi pada katalis kanan terbawa aliran dan memanaskan katalis kiri.

Melihat pola yang serupa antara profil dinamik temperatur pada katalis kiri dan kanan pada RFR, maka gambar selanjutnya pada simulasi prosedur start-up hanya akan menampilkan profil temperatur katalis bagian kiri saja. Temperatur maksimum katalis pada RFR dengan kondisi tersebut mencapai $1557{ }^{\circ} \mathrm{C}$. Katalis dan reaktor akan mengalami kerusakan pada temperatur tersebut. Oleh karena itu, perlu ada prosedur pengambilan panas dari RFR.

\subsection{Prosedur start-up}

Berdasarkan simulasi yang telah dilakukan pada operasi unggun searah, kondisi temperatur awal untuk prosedur start-up ditetapkan pada Tabel 3. 
Tabel 3. Kondisi temperatur awal berbagai prosedur start-up

\begin{tabular}{lccc}
\hline \multirow{2}{*}{ Kondisi } & \multicolumn{3}{c}{ Prosedur start } \\
\cline { 2 - 4 } & $\mathbf{1}$ & $\mathbf{2}$ & $\mathbf{3}$ \\
\hline Temperatur awal inert kiri, ${ }^{\circ} \mathrm{C}$ & 30 & 500 & 500 \\
Temperatur awal katalis kiri, ${ }^{\circ} \mathrm{C}$ & 500 & 500 & 500 \\
Temperatur awal inert kanan, ${ }^{\circ} \mathrm{C}$ & 30 & 30 & 500 \\
Temperatur awal katalis kanan, ${ }^{\circ} \mathrm{C}$ & 500 & 30 & 500 \\
Temperatur umpan, ${ }^{\circ} \mathrm{C}$ & 30 & 30 & 30 \\
\hline
\end{tabular}

3.2.1 Pemanasan katalis (prosedur startup 1)

Prosedur start-up 1 dengan hanya memanaskan bagian katalis saja baik bagian kiri maupun kanan pada oksidasi katalitik metana pada temperatur $500{ }^{\circ} \mathrm{C}$, ternyata tidak mampu mencapai kondisi ototermal. Hanya dalam waktu 10 detik sejak umpan inert juga tidak besar. Dengan kata lain, laju pembentukan panas sangat kecil dibandingkan dengan laju penyebaran panas ke unggun dan terbawa aliran keluar reaktor sehingga membuat reaksi akhirnya segera padam (Gambar 7).

Jika Gambar 7 diperhatikan lebih seksama, saat dilakukan pembalikan pada detik ke-50 temperatur katalis bagian kanan berada pada temperatur $46{ }^{\circ} \mathrm{C}$, kemudian berangsur-angsur temperatur katalis naik hingga mencapai $85{ }^{\circ} \mathrm{C}$ pada detik ke-83. Besar kemungkinan pada ST yang sangat rendah, kondisi ototermal dapat tercapai. Namun, sayangnya pada ST rendah konversi total selama start-up dan bahkan setelah kondisi tunaknya tercapaipun akan menurun, karena frekuensi terjadinya slip metana (peristiwa tidak bereaksinya umpan pada bagian inert saat pembalikan arah karena terdorong kembali ke luar reaktor) akan semakin tinggi.

\subsubsection{Pemanasan inert dan katalis bagian kiri (prosedur start-up 2)}

Pemanasan awal inert dan katalis bagian kiri saja pada temperatur $500{ }^{\circ} \mathrm{C}$ mampu menciptakan kondisi ototermal dalam reaktor untuk ST 100 dan 200 detik (Gambar 7). Umpan bertemperatur lingkungan akan memperoleh panas dari inert bagian kiri dan siap bereaksi pada bagian katalis. Sementara itu, inert bagian kanan akan memperoleh panas dari hasil reaksi. Semakin lama reaksi berlangsung, temperatur inert bagian kiri akan semakin menurun sehingga dibutuhkan pembalikan bertemperatur lingkungan masuk dari sebelah kiri temperatur katalis turun dari $500{ }^{\circ} \mathrm{C}$ menjadi $116^{\circ} \mathrm{C}$. Hal ini terjadi karena panas yang dihasilkan oleh pembakaran metana encer tidak terlampau besar mengingat temperatur umpan yang rendah dan panas standar pembakaran relatif kecil sehingga panas yang dapat disebarkan ke arah agar umpan dapat tetap pada kondisi siap bereaksi saat menyentuh katalis.

Switching time memegang peranan penting dalam menjamin RFR berada dalam kondisi ototermal. ST yang terlalu lama akan membuat reaksi menjadi padam, seperti pada ST 300 detik (Gambar 8). Untuk kondisi pada prosedur start-up 2, ST maksimum yang diperbolehkan agar RFR masih berada dalam keadaan ototermal adalah 230 detik.

Waktu pencapaian kondisi tunak semu untuk ST yang lebih singkat ternyata menunjukkan waktu yang lebih lama. Dengan ST yang lebih singkat berarti RFR semakin sering mendapatkan gangguan. Pada ST 200 detik, kondisi tunak semu tercapai dalam waktu 1000 detik. Sedangkan ST 100 detik hingga waktu 1600 detik pun masih tampak terjadinya kecenderungan peningkatan temperatur katalis (Gambar 8).

\subsubsection{Pemanasan seluruh bagian reaktor (prosedur start-up 3)}

Pemanasan awal seluruh bagian reaktor pada temperatur $500{ }^{\circ} \mathrm{C}$ membuat rentang ST ototermal semakin lebar. Dengan prosedur start-up 3, RFR masih berada dalam kondisi ototermal hingga ST 300 detik (Gambar 9). Pada ST lebih besar dari 300 detik reaktor akan padam seperti terlihat pada Gambar 9 untuk ST 600 detik. Pengamatan lebih jauh terhadap kurva untuk ST 300 detik sebagai batas ST ototermal menunjukkan terjadinya penurunan temperatur katalis hingga mencapai $73^{\circ} \mathrm{C}$ pada waktu pembalikan arah. Pada temperatur kritis tersebut umpan harus segera dibalik agar reaksi tidak padam. 


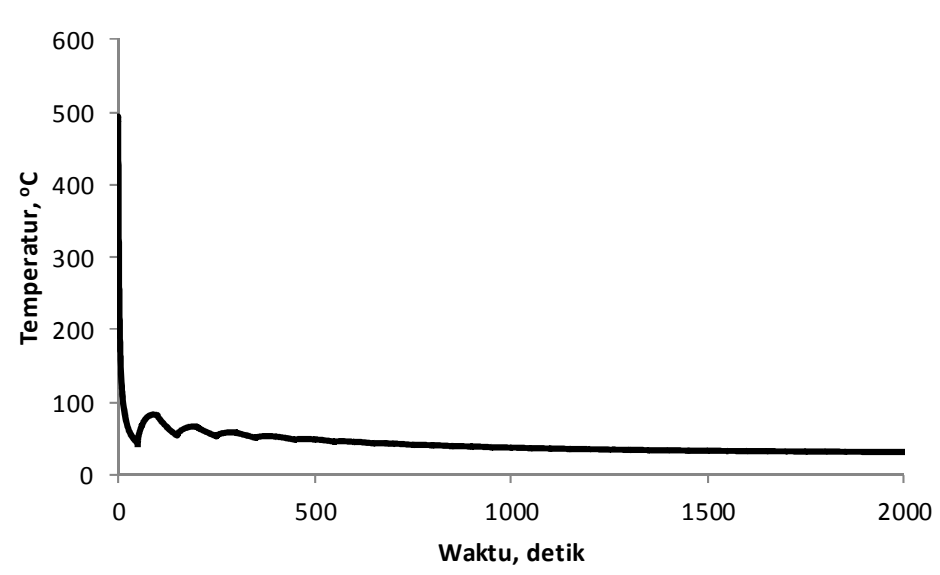

Gambar 7. Profil dinamik T katalis RFR untuk prosedur start-up 1 padaST 50 detik

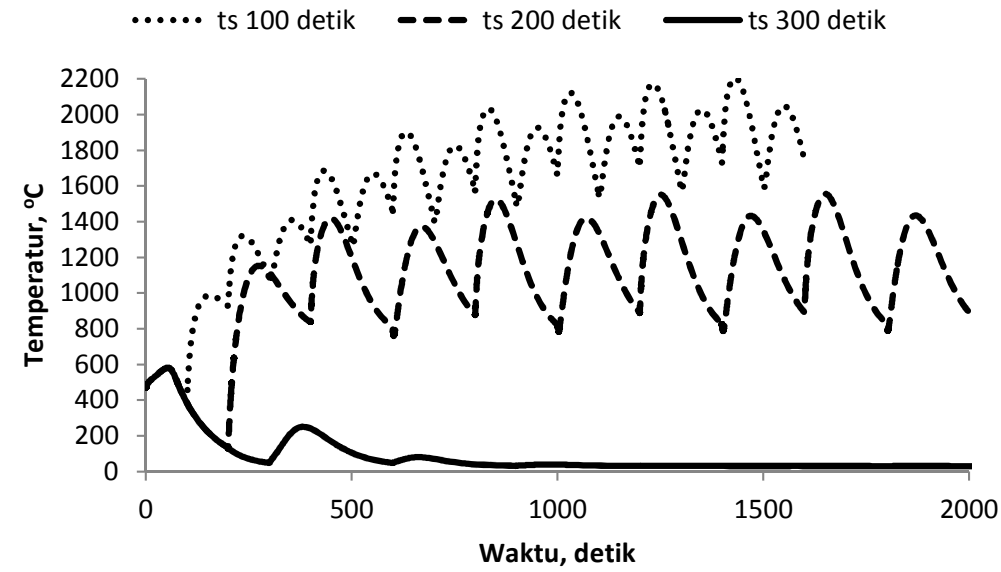

Gambar 8. Profil dinamik T katalis RFR untuk prosedur start-up 2 pada ST 100, 200, dan 300 detik

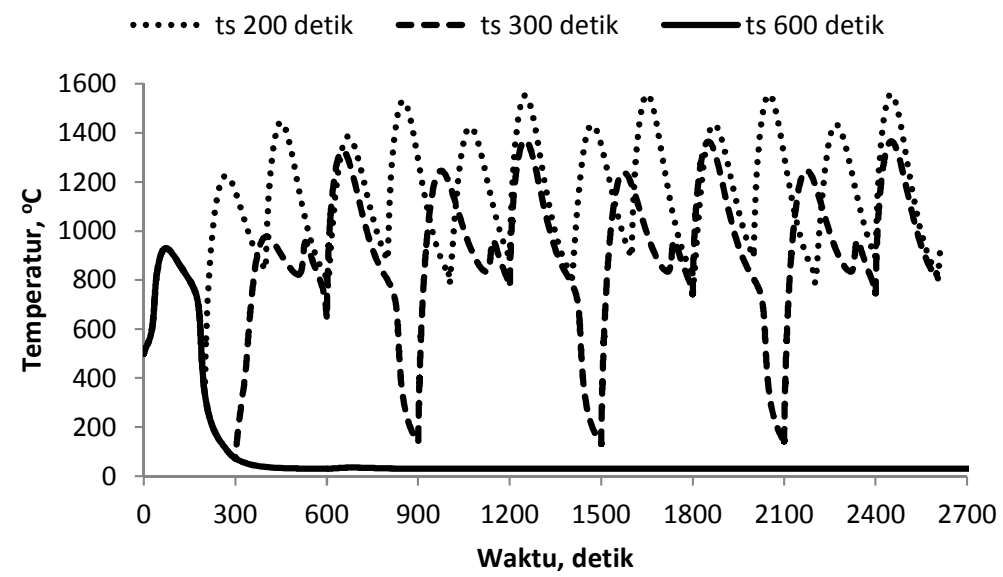

Gambar 9. Profil dinamik T katalis RFR untuk prosedur start-up 3 pada ST 200, 300, dan 600 detik 
Tabel 5. Perbandingan unjuk kerja RFR untuk berbagai prosedur start-up

\begin{tabular}{lccc}
\hline \multirow{2}{*}{ Parameter unjukkerja } & \multicolumn{3}{c}{ Prosedurstart-up } \\
\cline { 2 - 4 } & $\mathbf{1}$ & $\mathbf{2}$ & $\mathbf{3}$ \\
\hline Kebutuhan panas, Joule & 579 & 5068 & 10136 \\
Waktu untuk mencapai kondisi tunak & padam & 1000 & 1000 \\
semu, detik* $^{*}$ T maksimum, ${ }^{\circ}{ }^{*}$ & & & \\
Konversi selama ${\text { start- } u p^{*}}_{\text {ST maksimum ototermal, detik }}^{500}$ & 1555 & 1557 \\
ST minimum ototermal, detik & - & $95 \%$ & $99 \%$ \\
\hline
\end{tabular}

*untuk ST 200 detik

** waktu tinggal gas dalam katalis

Secara keseluruhan perbandingan unjuk kerja RFR ketiga prosedur start-up dirangkum dalam Tabel 5 khususnya untuk ST 200 detik. Prosedur start-up 2 dan 3 mampu mencapai kondisi ototermal dengan konversi total selama pencapaian kondisi tunak semu masing-masing $95 \%$ dan $99 \%$. Namun, kenaikan konversi sebesar $4 \%$ itu harus dikompensasi dengan kenaikan beban panas dari $5069 \mathrm{~J}$ untuk Prosedur start-up 2 menjadi dua kali lipatnya yaitu $10136 \mathrm{~J}$ pada Prosedur start-up 3. Sementara itu, Prosedur start-up 1 tidak mampu menyelenggarakan reaksi secara ototermal pada ST 200 detik dan temperatur awal $500^{\circ} \mathrm{C}$. Kondisi ototermal hanya dapat tercapai pada ST yang cepat dengan konversi total yang sangat rendah. Dengan demikian dapat dinyatakan bahwa Prosedur start-up 2 memiliki keuntungan lebih daripada 2 prosedur lainnya.

\section{Kesimpulan}

Berbagai prosedur start-up RFR telah dikaji dalam penelitian ini. Prosedur start-up yang baik dapat membuat reaksi beroperasi secara ototermal, konversi metana tinggi, waktu pencapaian kondisi tunak semu (pseudosteady state) cepat, dan beban panas rendah. Secara umum, unjuk kerja RFR selama periode start-up dipengaruhi oleh switching time dan prosedur start-up. Prosedur start-up 2, yaitu pemanasan awal katalis dan inert bagian kiri saja, lebih unggul daripada Prosedur start-up 1 dan 3. Prosedur start-up 1, yaitu pemanasan awal kataliskatalisnya saja, gagal melangsungkan reaksi yang bersifat ototermal dan berkonversi tinggi. Prosedur start-up 3, yaitu pemanasan seluruh bagian reaktor memberikan rentang ST relatif lebih lebar.

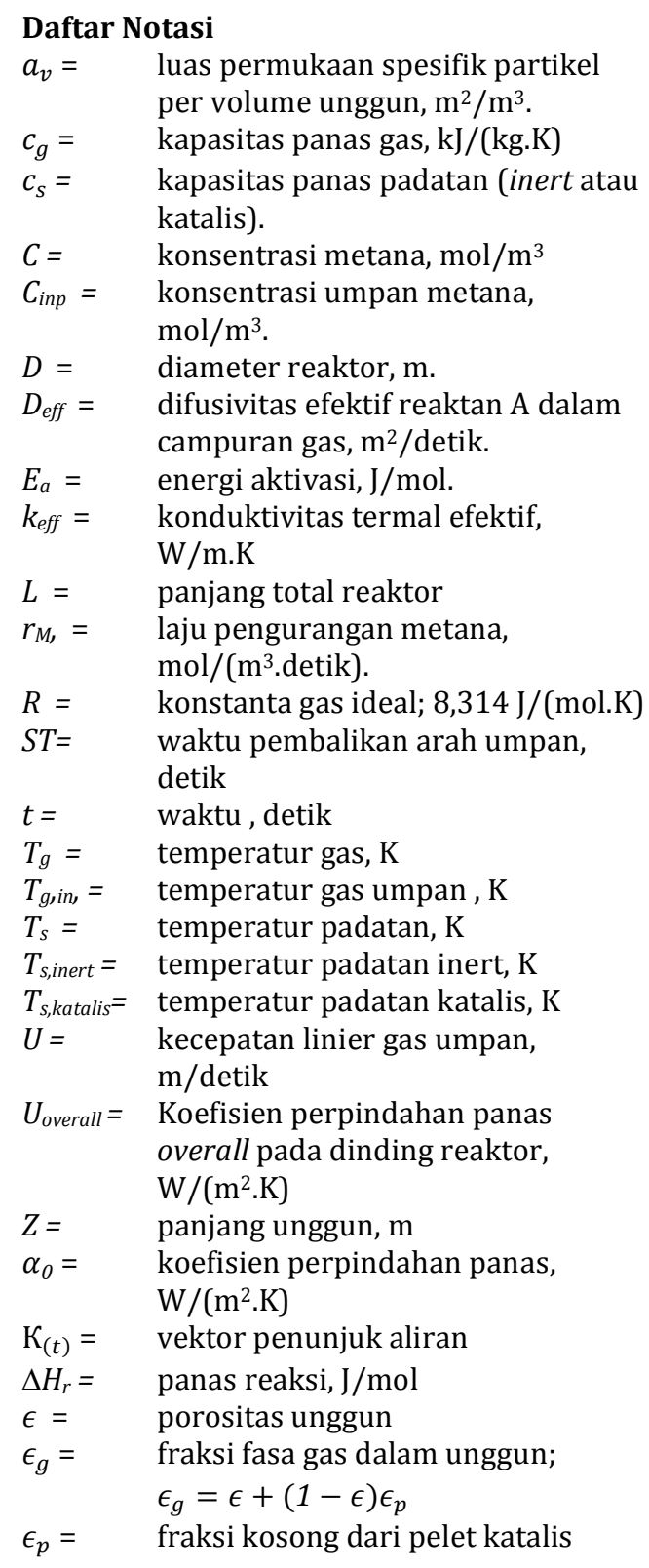


$\epsilon_{s}=\quad$ fraksi fasa padat dalam unggun;

$\epsilon_{s}=(1-\epsilon)\left(1-\epsilon_{p}\right)$

$\rho_{g}=\quad$ densitas gas, $\mathrm{kg} / \mathrm{m}^{3}$

$\rho_{s}=\quad$ densitas padatan, $\mathrm{kg} / \mathrm{m}^{3}$

\section{Daftar Pustaka}

Balaji, S.; Lakshminarayanan, S. Heat removal from reverse flow reactors used in methane combustion. The Canadian Journal of Chemical Engineering. 2005, 83.

Baressi, A. A.; Baldi, G; Fissore, D. Forced Unsteady-State Reactors as Efficient Devices for Integrated Processes: Case Histories and New Perspectives. Industrial \& Engineering Chemistry Research. 2007, 46(25).

Bosomiu, M.; Bozga, G.; Soare, G. Methane Combustion Over a Commercial Platinum on Alumina Catalyst: Kinetics and Catalyst Deactivation. Revue Roumaine de Chimie. 2008, 53(12), 1105-1115.

Effendy, M.; Budhi, Y. W.; Bindar, Y.; Subagjo. Penentuan metode operasi reverse flow reactor dengan umpan fluktuatif dalam pengolahan emisi gas metana di stasiun kompresor, Prosiding SNTKI, Bandung, Indonesia, 19-20 Oktober 2009.

Eigenberger, G.; Nieken, U. Catalytic Combustion with Periodic Flow Reversal. Chemical Engineering Science. 1988, 43, 2109-2115.

Gawdzik, A.; Rakowski, L. The methods of analysis of the dynamic properties of the adiabatic tubular reactor with switch flow. Computers Chemical Engineering. 1989, 13 (10), 1165-1173.

Hayes, R. E.; Kolaczkowski, S. T.; Introduction to catalytic combustion, Gordon and Breach, Amsterdam, 1997.

Hayes, R. E.; Kolaczkowski, S. T.; Li, P. K.; Awdry, S. The palladium catalyzed oxidation of methane: reaction kinetics and the effect of diffusion barriers. Chemical Engineering Science. 2001, 56, 4815-4835.

Hayes, R. E. Catalytic solutions for fugitive methane emissions in the oil and gas sector. Chemical Engineering Science. 2004, 59, 4073-4080.
Kushwaha, A.; Poirier, M.; Sapoundjiev, H.; Hayes, R. E. Effect of reactor internal properties on the performance of a flow reversal catalytic reactor for methane combustion. Chemical Engineering Science. 2004, 59, 4081-4093.

Kolios G.; Frauhammer, J.; Eigenberger, G. Review Autothermal fixed-bed reactor concepts. Chemical Engineering Science. 2000, 55, 5945-5967.

Lee, J. H.; Trimm, D. L. Catalytic combustion of methane. Fuel Processing Technology, 1995, 42, 339-359.

Litto, R.; Hayes, R. E.; Liu, B. Capturing fugitive methane emissions from natural gas compressor buildings, Journal of Environmental Management. 2006, 84 (3), 347-361.

Matros, Y. S; Bunimovich, G. A. Reverse flow operation in fixed bed catalytic reactors. Catal. Rev.-sci. eng. 1996, 38 (1), 1-68.

Moore, S.; Freund, P.; Riemer, P.; Smith, A.; Abatement of methane emissions, IEQ Greenhouse Gas R\&D Programme, Cheltenham, 1998.

Otto, K. Methane Oxidation over Pt on $\gamma$ Alumina: Kinetics and Structure Sensitivity. Langmuir. 1989, 5, 1364-1369.

Annonymous. FlexPDE 6, PDE Solutions Inc, 2006.

Salomons, S.; Hayes, R. E.; Poirier, M.; Sapoundjiev, H. Flow reversal reactor for catalytic combustion of lean methane mixtures. Catalysis Today. 2003, 83, 59-69.

Sapoundjiev, H.; Aube, F.; Catalytic flow reversal reactor technology: an opportunity for heat recovery and greenhouse gas elimination from mine ventilation air, Canmet energy technology centre, Varennes, Canada, 1999.

Schäfer, M.; Computational Engineering Introduction to Numerical Methods, Springer, Berlin, 2006; p. 107. 